\title{
Performance of Geopolymer Concrete at High Temperature
}

\author{
K. Lokesh ${ }^{1}$ | K K V D Prasad ${ }^{2}$
}

${ }^{1}$ PG Student, Dept of Civil Engineering, Vikas Group of Institutions, Vijayawada, India 2Professor, Dept of Civil Engineering, Vikas Group of Institutions, Vijayawada, India

To Cite this Article

K. Lokesh, K K V D Prasad, "Performance of Geopolymer Concrete at High Temperature”, International Journal for Modern Trends in Science and Technology, Vol. 06, Issue 07, July 2020, pp.:165-169; https://doi.org/10.46501/IJMTST060727

\section{Article Info}

Received on 11-June-2020, Revised on 27-June-2020, Accepted on 18-July-2020, Published on 25-July-2020.

\section{ABSTRACT}

Production of concrete cause semanationo fan equal measure of Carbon dioxide, which is an ozone depleting substance into environment causing a worldwide temperature alteration. Fly debris and ground granulated impact heater slag (GGBS) has cementations material properties and consequently can be utilized as substitute material for concrete to beat the natural issues. During power age in warm plants huge amount of fly debris is created as a waste item, removal of which is issue and correspondingly GGBS is delivered in steel plants. Normal waterway sand isn't accessible to meet the necessity and furthermore costlier because of the constrained just as unlawfuldigging. Thus produced sand is utilized as another for stream sand. Geo-polymer is normally known as inorganic aluminum -hydroxide polymer which is blended dominatingly from silicon and aluminum particles in fly debris and GGBS. Structures like private structures, business structures like film lobbies, workplaces, ventures, shopping centers, lodgings, schools, clinics, burrows, oil wells and so forth, might be inclined to fire mishap at any timeframe during theiradministration. Consequently in this examination an endeavor is made to consider the compressive quality and flexural quality of geo-polymer concrete made of class $F$ fly debris, GGBS, $M$ sand, utilizing Sodium Hydroxide and Sodium Silicate arrangements as salt activators in various blend extents and the examples are exposed to warm relieving at $60^{\circ} \mathrm{C}$ and $70^{\circ} \mathrm{C}$ with various proportion so the activatorarrangements and molarities of soluble arrangement presented to raised temperature.

Keywords: GGBS, Fly Ash, Geo - Polymer, M Sand, Sodium hydroxide, Sodium Silicate.

Copyright (C) 2020 International Journal for Modern Trends in Science and Technology

DOI: https://doi.org/10.46501/IJMTST060727

\section{INTRODUCTION}

Concrete is one of the usually utilized synthetic structure materials, and is second just to water. Portland concrete is the primary cement establishing segment. Concretecreationisn'tjustvitalityescalatedyetadditi onally answerable for noteworthy measures of carbon dioxide (CO2) outflows. Because of calcination of calcite and ignition of petroleum product, the measure of carbon dioxide discharged during OPC fabricate is in the request for one ton for every ton of OPC made. Additionally, the measure of vitality required to make OPC is just close to steel and aluminum.Malhotra (2004) has noted two different ways to antagonistically influence nature because of mechanical. Changes in China and India. The utilization of less normal assets, lower vitality utilization and a decrease of $\mathrm{CO} 2$ discharges is recommended to fabricate earth 
economical cement. It was likewise conceivable to take out $\mathrm{CO} 2$ fromthe concrete business by diminishing the measure of calcined content in concrete, diminishing solid concrete sums and expanding the quantity of structures that utilization concrete cement.

\section{Methodology}

This chapter provides details of the various materials used in this concrete, casting method, curing specimens, exposure to elevated temperature and details of the various tests performed in relation to the present research.

\section{MATERIALS USED}

Fly ash: The dust collection system extracts fly ash from the combustion gases, either using electrostatic precipitators or by manually, until it is released into the atmosphere as shown in Figure 13. Fly ash particles are spherical generally, and are mostly finer than OPC and chalk, varying from $1-150 \mu \mathrm{m}$ indiameter.The different forms and concentrations of non- combustible matter of coal decide the chemical composition of fly ash which mainly consists of silicon ( $\mathrm{SiO} 2)$, iron (Fe2O3), aluminum (A12O3) and calcium $(\mathrm{CaO})$ oxides, while sodium, magnesium, potassium, Sculpture and titanium are also present in lower amounts.

GGBS: Ground granulated blast furnace slag (GGBS)is a by-product in steel plants which is produced by rapid coolingofmoltensteelwithwatermoisture.

Itisconsidered to produce beneficial factors for the concrete industry, as it is retaining excellent thermal properties, highly resistance to chemical attack and fairly inexpensive to produce. The $\mathrm{SiO2}$, $\mathrm{CaO}, \mathrm{MgO}$ and $\mathrm{AI} 2 \mathrm{O} 3$ are major components of the slag component. Chemical composition ofGGBS.Chemical shrinkage along with the volumeofporosityareconsiderablyhigherinsaturate dGGBS pastes and are a valid during setting period than in cement pastes. Drying shrinkage results directly from hydration heat, and water glass activator dosage and increases with increased module.

Alkaline solutions: Alkaline solutions plays a significant role in geopolymer concrete. In this study sodium base solutions are used in order to get the best results, AL-Si minerals are more soluble in sodium based solutionsandtheyarealsomuchcheaperwhencompa redto that of potassium based solutions. Mostly, combination of sodium base solutions are preferred than using onlysodium silicate or sodium hydroxide. Combination of alkaline solution used is $\mathrm{NaOH}$ and $\mathrm{Na2SiO3.With}$ ratio content $(\mathrm{Na} 2 \mathrm{SiO} 3 / \mathrm{NaOH})$ at 2 and 2.5.To obtain a concentration of 12 molarity, molecular weight 40 is

multipliedbymolaritywhichgives 480 gramsofpellets and are to be dissolved in 1 litre ofwater.

Sodium hydroxide: Sodium hydroxide is acquired from a local store which is in pellets form and having 99\% purity as shown in Figure 15. The pellets are spherical in shape, small in size and contains compressed mass of sodium hydroxide. The mass of sodium hydroxide pellets are dissolved in water for preparation of solution with particular molarity and expressed in terms of molarM.

Sodium silicate: Silicate is obtained from a locally available store in a liquid form. This is a common name

of

compoundsodiummetasilicatewhichiscommonlyter med

asliquidglassorwaterglasswhichisslightlygreyincolo $r$ containing at least $55-57 \%$ ofwater.

Manufactured sand: The Manufactured Sand (MS) is a-product of the quarrying crushing and screening process. Quarry produces significant quantities of quarry fines when grindingthebluegraniterockintoaggregates. Thisisal socalled crushed sand of granite stone, stone sand, and crusher fine aggregate, and crushedsand.

Coarse aggregate: In this study, coarse aggregate of size $20 \mathrm{~mm}$ conforming to IS: 383- 1970 is use. To assess the specific gravity of aggregates, pycnometer test is performed. Sieveanalysiswasdonetofindtheaggregatefineness modulus and material retained on $4.75 \mathrm{~mm}$ sieve and passed through $20 \mathrm{~mm}$ sieve is utilized for the experiment. The surface area ofthe coarse aggregate is less than that of the fineaggregate.

Admixture: Naphthalene based admixture is used for the geopolymer concrete to improve the workability of the concrete. Superplasticizersareadditivesusedinprod ucinghigh strength concrete, also known as high range water reducers. Plasticizers are chemical compounds that allow concrete to be manufactured at 15 percent lower water content. Superplasticizers require a 30 percent or more reduction in water content. Most of the water gets entrapped between the cement particles in a usual mix. SO, by adding a super plasticizer the water entrapped there gets free and it involvesin the hydration of cement and thus improves the 
strength. It also improves the work ability of concrete by improved slump value. BASF master ease 3708 is used as super plasticizer.

\section{MIX DESIGN}

Mix design can be defined as the process of selecting suitable ingredients of concrete and determining the relative proportions with the objective of producing concrete of certain minimum strength and durability as economically as possible. There are many methods available for mix design. Here Indian Standard Method, based on IS10262:200 is adopted. Mix design for control cubes, composite cubes for which the cement was partially replaced with fly ash.

\section{Mix Proportions}

\begin{tabular}{|c|c|c|c|c|}
\hline S.NO & \multicolumn{2}{|c|}{ MATERIALS } & MIX 1 & MIX 2 \\
\hline \multirow[b]{2}{*}{1} & \multirow[b]{2}{*}{ Binding agents } & Fly ash & 206 & 206 \\
\hline & & GGBS & 206 & 206 \\
\hline 2 & Fine Aggregate & & 688 & 688 \\
\hline 3 & Coarse Aggregate & & 1253 & 1253 \\
\hline \multirow[t]{2}{*}{4} & \multirow{2}{*}{$\begin{array}{l}\text { Alkaline activator } \\
\text { solution }\end{array}$} & $\begin{array}{c}\text { Sodium } \\
\text { hydroxide }\end{array}$ & 62 & 53.13 \\
\hline & & Sodium silicate & 125 & 131.7 \\
\hline 5 & Super Plasticizer & & 4.18 & 4.18 \\
\hline
\end{tabular}

\section{RESUlts AND Discussion}

\section{Compressive Strength}

The test results of strength in compression for different molarities and different ratios of $\mathrm{NaOHand} \mathrm{Na2SiO3.}$

\begin{tabular}{|c|c|c|c|c|}
\hline \multirow{2}{*}{$\begin{array}{c}\text { Molarity/ Ratio } \\
\left(\mathrm{NaOH} / \mathrm{Na}_{2} \mathrm{SiO}_{3}\right)\end{array}$} & \multicolumn{2}{|c|}{ At $60^{\circ} \mathrm{C}$} & \multicolumn{2}{|c|}{ At $70^{\circ} \mathrm{C}$} \\
\hline & $1: 2$ & $1: 2.5$ & $1: 2$ & $1: 2.5$ \\
\hline $12 \mathrm{M}$ & $50.18 \mathrm{~N} / \mathrm{mm}^{2}$ & $51 \mathrm{~N} / \mathrm{mm}^{2}$ & $51 \mathrm{~N} / \mathrm{mm}^{2}$ & $52 \mathrm{~N} / \mathrm{mm}^{2}$ \\
\hline $16 \mathrm{M}$ & $61.8 \mathrm{~N} / \mathrm{mm}^{2}$ & $51 \mathrm{~N} / \mathrm{mm}^{2}$ & $53.4 \mathrm{~N} / \mathrm{mm}^{2}$ & $50.2 \mathrm{~N} / \mathrm{mm}^{2}$ \\
\hline $20 \mathrm{M}$ & $55.9 \mathrm{~N} / \mathrm{mm}^{2}$ & $51.3 \mathrm{~N} / \mathrm{mm}^{2}$ & $51.9 \mathrm{~N} / \mathrm{mm}^{2}$ & $47.9 \mathrm{~N} / \mathrm{mm}^{2}$ \\
\hline
\end{tabular}

5.1.2 Effect of concentration of Sodium hydroxide solution

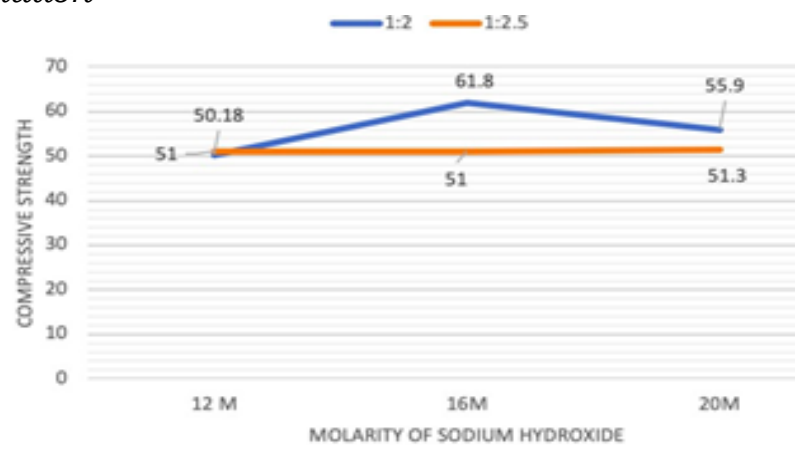

Fig 1: Variation of compressive strength of geopolymer concrete heat at $60^{\circ} \mathrm{C}$

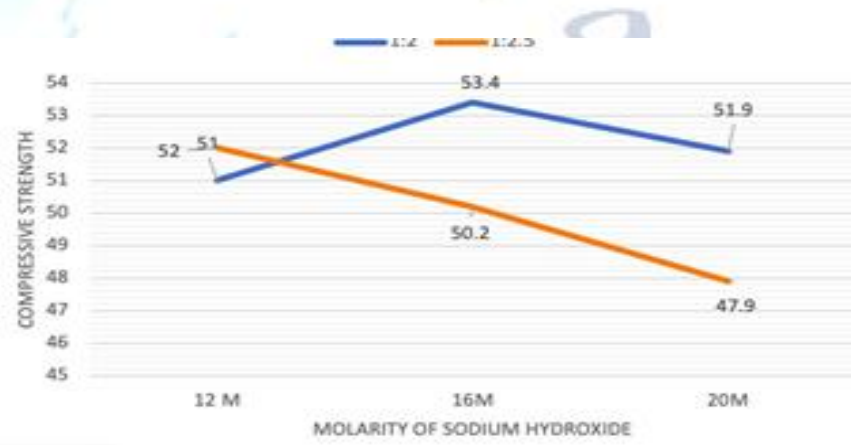

Fig 2:Variation of compressive strength of geopolymer concrete at $70^{\circ} \mathrm{C}$

\begin{tabular}{|c|c|c|c|c|}
\hline \multirow{2}{*}{$\begin{array}{l}\text { Molarity/ Ratio } \\
\left(\mathrm{NaOH} / \mathrm{Na}_{2} \mathrm{SiO}_{3}\right)\end{array}$} & \multicolumn{2}{|c|}{ At $60^{\circ} \mathrm{C}$} & \multicolumn{2}{|c|}{ At $70^{\circ} \mathrm{C}$} \\
\hline & $1: 2$ & $1: 2.5$ & $1: 2$ & $1: 2.5$ \\
\hline $12 \mathrm{M}$ & $3.1 \mathrm{~N} / \mathrm{mm}^{2}$ & $3.3 \mathrm{~N} / \mathrm{mm}^{2}$ & $3.09 \mathrm{~N} / \mathrm{mm}^{2}$ & $3.6 \mathrm{~N} / \mathrm{mm}^{2}$ \\
\hline $16 \mathrm{M}$ & $3.3 \mathrm{~N} / \mathrm{mm}^{2}$ & $3.6 \mathrm{~N} / \mathrm{mm}^{2}$ & $3.1 \mathrm{~N} / \mathrm{mm}^{2}$ & $3.7 \mathrm{~N} / \mathrm{mm}^{2}$ \\
\hline $20 \mathrm{M}$ & $3.1 \mathrm{~N} / \mathrm{mm}^{2}$ & $3.5 \mathrm{~N} / \mathrm{mm}^{2}$ & $3.2 \mathrm{~N} / \mathrm{mm}^{2}$ & $3.3 \mathrm{~N} / \mathrm{mm}^{2}$ \\
\hline
\end{tabular}

\section{Ratio of Sodium hydroxide to Sodiumsilicate solution on compressivestrength}

Decrease in sodium silicate increases the strength effectively in the case 600 Celsius curing and slight increment for 700 Celsius. Therefore irrespective of molarity of $\mathrm{NaOH}$ and the curing period compressive strength of geopolymer concrete subjected to an elevated temperatureof2000Cstrengthoftheconcreteincreas eswith more sodium hydroxide content. 
A. Effect of curing temperatures on compressive strength

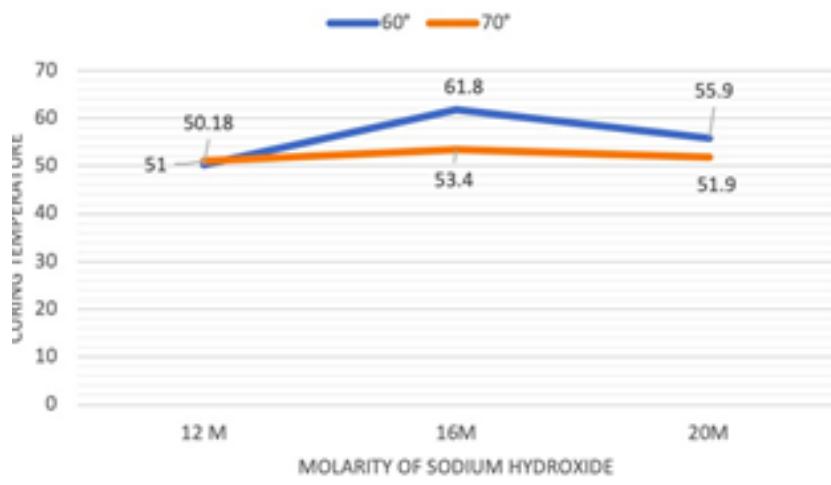

Fig 3: Variation of compressive strength of geopolymer concrete at alkaline solutionRatio 1:2 $\left(\mathrm{NaOH} / \mathrm{Na}_{2} \mathrm{SiO}_{3}\right)$

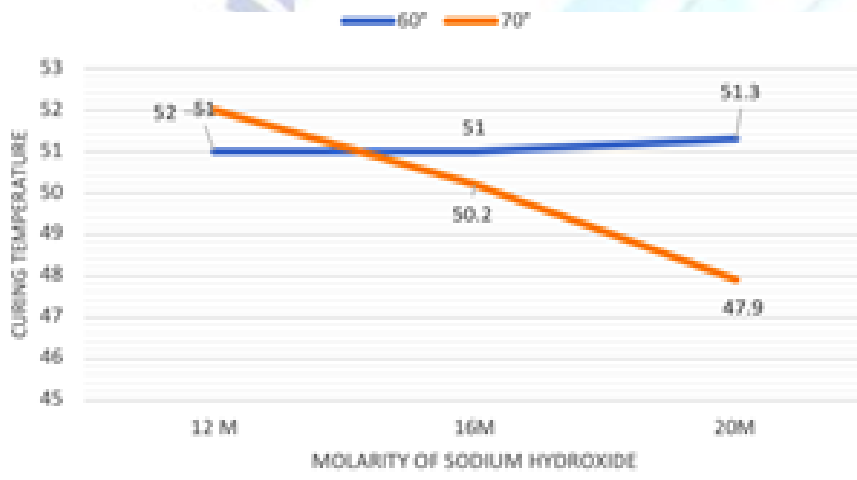

Fig 4: Variation of compressive strength of concrete at alkaline solutionRatio 1:2.5 $\left(\mathrm{NaOH} / \mathrm{Na}_{2} \mathrm{SiO}_{3}\right)$

\subsection{Flexural strength:}

\section{Effect of concentration of Sodiumhydroxide solution on flexuralstrength}

\section{$-1: 2-1: 2$}

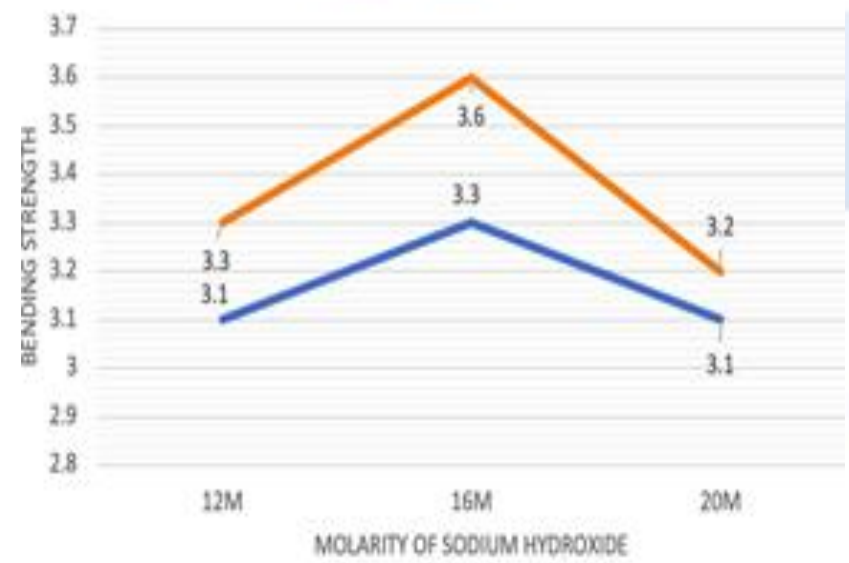

Fig 5: Variation of flexural strength of geopolymer concrete heat cured at $60^{\circ} \mathrm{C}$

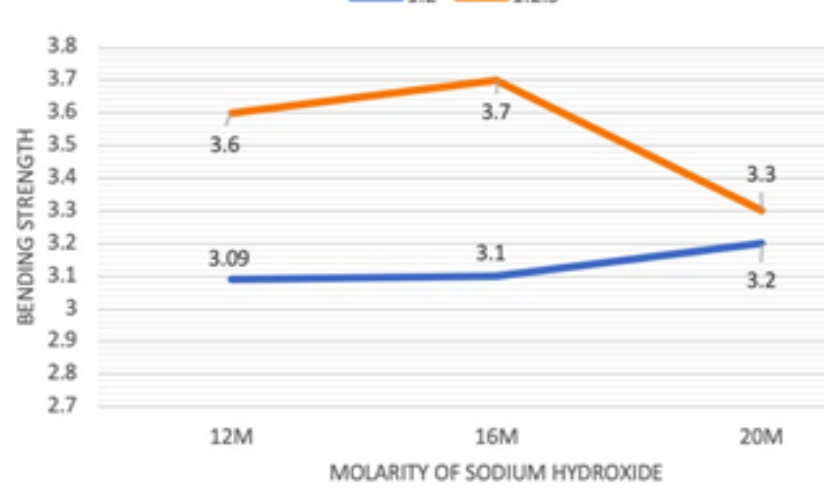

Fig 6: Variation of flexural strength of geopolymer heat cured at $70^{\circ} \mathrm{C}$

\section{Ratio of Sodium hydroxide to Sodiumsilicate solution on flexuralstrength}

Increase in sodium silicate increases the bending strength of beams in all the cases by at least an average of $15 \%$ increment can be seen.

B. Effect of curing temperatures on flexuralstrength

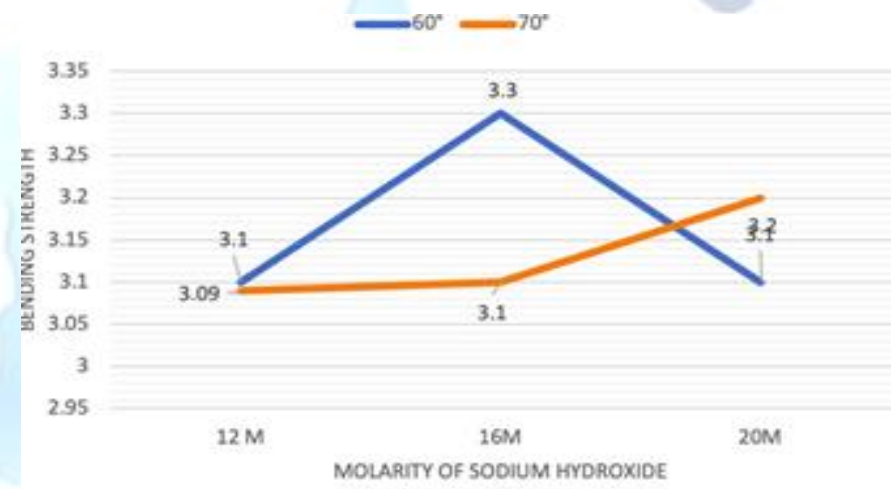

Fig 7: Variation of flexural strength of geopolymer concrete at alkaline solutionRatio 1:2

$\left(\mathrm{NaOH} / / / \mathrm{Na}_{2} \mathrm{SiO}_{3}\right)$

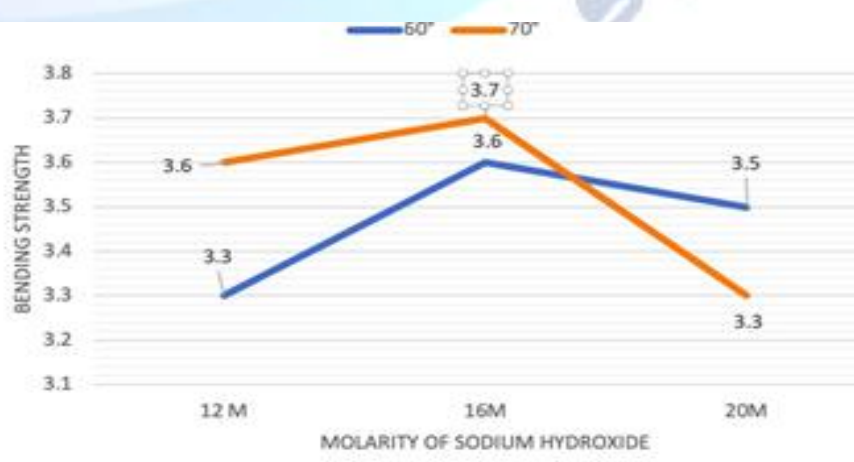

Fig 8: Variation of flexural strength of geopolymer concrete at alkaline solutionRatio 1:2.5

$\left(\mathrm{NaOH} / / / \mathrm{Na}_{2} \mathrm{SiO}_{3}\right)$ 


\section{Conclusion}

The application of fly as hand GGBS in concrete can be extended to many structures which are subjected to elevated temperatures. The available literature that reveals the behaviour of geo polymer concrete exposed to elevated temperatures is very less, which initiated the necessity of study of geo polymer concrete exposed to elevated temperatures. Hence in this study, geo polymer concrete at age of 28 days exposed to temperatures of 200o $\mathrm{C}$ for $1 \mathrm{~h}$ duration. The effect of elevated temperatureson the properties of concrete such as compressive strength and flexural strength are studied the experimental results have revealed the followingconclusions.

1. In the context of this analysis, it is observed that geopolymer concrete at $16 \mathrm{M}$ of $\mathrm{NaOH}$ with alkaline ratio of $1: 2(\mathrm{NaOH} / \mathrm{Na} 2 \mathrm{SiO} 3)$ at 600 Celsius tends to have high strength in compression when exposed to elevatedtemperature of 2000 Celsius.

2. Curing in oven at 600 Celsius yields maximum strength in compression for geopolymer concrete even after subjected to elevated temperature proving to have high thermalresistance.

3. An early development in strength of geopolymerconcrete can be obtained by selecting proper curing temperature and curingperiods.

4. The least compressive strength is obtained for 20 molar sodium hydroxide cured at 700 Celsius with 1:2.5 (NaOH/Na2SiO3) alkaline ratio with a strength ofabout

$48.3 \mathrm{~N} / \mathrm{mm} 2$.

5. The flexural strength in geopolymer concrete whenexposed to high temperature occurred two times, i.e., at 16 molarity having a ratio of $1: 2.5$ at 700 Celsius and at 20 molar with a alkaline solution ratio of $1: 25$ cured at 700 Celsius. Here we can observe that except the molarity parameter other parameters are constant stating that bending strength can be improved by alkaline ratio of $1: 2.5$ and curing temperature of 700 Celsius.

6. Lowest flexural strength is observed at 12 molarity of sodium hydroxide with a alkaline ratio of $1: 2$ at 600 Celsius having less thermal resistance in geopolymerconcrete.

7. Increase in sodium silicate content tends to improve the beam bending strength properties and improves even better with high curingtemperature. With increase in sodium silicate content flexural strength of GPC increased while there is adecrease in compressive strength which can be noticed from the results. Even at elevated temperature geopolymer concrete gains highstrength.

\section{REFERENCES}

[1] Choate, W.T. (2003). "Energy and Emission Reduction Opportunities for the Cement Industry", Report: Industrial Technological Program, Energy Efficiency and Renewable Energy, US Department of Energy,USA.

[2] Davidovits.J (1994)."High-AlkaliCementsfor21stCentury Concretes",ACISpecial Publication, 144, 383-398.

[3] Malhotra, V. M. (1999). "Making Concrete "Greener" With Fly Ash."ConcreteInternational, 21(5), 61-66.

[4] Cembureau.(2014)."QuarterlyEconomicreports-Keyfacts\& Figures",http://www.cembureau.be/about-cement/key-facts -figures, visited on 3.8.2015.

[5] India Brand Equity Foundation. (2015). "Indian Cement Industry

Analysis",http://www.ibef.org/industry/cement-presentat ion, visited on 3.8.2015.

[6] Worrell,E.,Price,L.,Martin,N.,Hendriks,C., andMeida,L.O. (2001). "Carbon Dioxide Emissions fromthe Global Cement Industry", Annual Review of Energy and Environment, 26(November),303-329.

[7] Central Electricity Authority. (2014). "Report on Fly ash generation at Coal/Lignite Based Thermal Power Stations AndIts Utilization in the Country, For the Years 2011-12 and 2012- 13", Central Electricity Authority Government of India, New Delhi.

[8] Lokeshappa, B., and Dikshit, A.K. (2011). "Disposal and Management of Fly ash", IPCBEE, 3(January), 11-14.

[9] Ken, P.W., Ramli, M., and Ban, C.C. (2015). "An overview on the influence of various factors on the properties of geopolymer concrete derived from industrial by-products", Construction and Building Materials, 77(February), 370-395.

[10] Olivia, M., and Nikraz, H.R., (2011). "Strength and Water Penetrability of Fly Ash Geopolymer Concrete", ARPN Journal of Engineering and Applied Sciences, 6(7),70-78.

[11] Rangan,B.V. (2011). "FlyAsh-BasedGeopolymerConcrete", Proceeding of the International Workshop on Geopolymer Cement and Concrete, Allied Publishers Private Limited, Mumbai, India,68-106.

[12] Davidovits, J., Francisco, A. (1981). "Fabrication of stone objects, by geopolymer synthesis, in the pre-IncanHuanka civilization (Peru)", Proceedings of the 21 stSymposium for Archaeometry at Brookhaven national Laboratory, New York, USA.

[13] Davidovits.J(1984). "X-RayAnalysisandX-RayDiffraction ofCasingStoneFromthePyramidsofEgypt, and theLimeStone of the Associated Quarries", Proceedings of the Science in Egyptology Symposia, Manchester, U.K.,511-520

[14] Jana, D. (2007). "The Great Pyramid debate: evidence from detailed petrographic examinations of casing stones from the Great Pyramid of Khufu, a natural limestone from Tura, and a man-made (geopolymeric) limestone, Proceedings of the 29thConference on Cement Microscopy, Quebec City,PQ.

[15] IS: 516-1959(Reaffirmed 1999) Indian Standard Methods of tests for strength of concrete. Bureau of Indian Standards, New Delhi,India. 